\title{
Culture de levure fourragère sur lactosérum de fromagerie et son influence sur la pollution des eaux
}

\author{
par \\ G. VERNOIS \\ Ingénieur-Conseil à Vanves (92)
}

C'est au cours de la première guerre mondiale qu'on se souvint à Berlin de la découverte fondamentale de Pasteur qui avait trouvé la possibilité de produire de la levure en introduisant de l'oxygène en forte quantité dans les solutions très diluées d'un mélange de mélasse sucrière et de sels nutritifs purement inorganiques et riches en azote (sels d'ammonium). On produisit de cette façon (en très faible quantité) de la levure fourragère (Torula utilis), dénommée par Delbrück et ses coll. " levure minérale ». La production de cette levure a connu un renouveau vers 1934 et elle est même devenue très importante pendant la deuxième guerre mondiale.

Ces derniers temps on s'y intéresse à nouveau; la raison en est que la levure fourragère, grâce à sa forte teneur en albumine (50 p. 100 env. de la matière sèche) et sa richesse en vitamines, est un excellent aliment du bétail. On l'utilise dans ce but en addition, à raison de 5 à 20 p. 100, au fourrage habituel. Une telle nourriture convient en particulier pour la volaille, les porcs et les porcelets. La production de cette levure est devenue relativement simple grâce aux procédés continus de fermentation.

\section{Le petit-lait comme matière première pour la fabrication de la levure fourragère}

Il peut être plus profitable pour une fromagerie de traiter le petit-lait afin d'en produire de la levure au lieu de le déverser tel quel dans la rivière la plus proche, ce qui contribue à la pollution de son eau et provoque des réclamations justifiées des riverains.

Car le petit-lait est un substrat très riche en toutes les matières nutritives pour la culture de la levure. Le lactosérum aigre ( $\mathrm{pH} 4,1)$ en produit la quantité principale et donne de meilleurs rendements que le lactosérum doux ( $\mathrm{pH}$ 6,3 à 6,5). Le lactosérum aigre renferme (à côté de 4 à 5,5 p. 100 de lactose, 0,5 à 1 p. 100 d'albumine et 0,1 p. 100 de matières grasses) encore 0,5 p. 100 d'acides lactique et citrique assimilables. Comme des quantités suffisantes de sels phospho- 
riques et potassiques y sont présentes, seuls des sels azotiques devront être ajoutés.

\section{Procédés de fabrication}

Les quatre procédés suivants sont généralement utilisés en vue de la production de la levure fourragère à partir du petit-lait : les procédés Linz, Polyvit, Waldhof et Biosyn, ce dernier pour la production du mycélium.

Le procédé Linz s'appuie sur la culture du levain et en utilise les installations analogues, par exemple l'aération par des tuyaux aérateurs. L'albumine du petit-lait est précipitée par échauffement à $85-90^{\circ} \mathrm{C}$ à un $\mathrm{pH} 4,7$ à 5,0 , c'est-a-dire au point iso-électrique, où on stérilise en même temps. Après addition d'ammoniac et de sulfate d'ammonium (en un rapport tel qu'une valeur $\mathrm{pH}$ de l'ordre de 4,2 à 4,4 se présente lors de la culture de la levure) et d'un peu de superphosphate en vue de la clarification, la levure est cultivée dans le lactosérum clair suivant le procédé d'afflux ou suivant le procédé de passage continu avec une maturation secondaire placée en aval. Le rendement en est de 12 à $15 \mathrm{~kg}$, au maximum de $20 \mathrm{~kg}$ de levure sèche pour $1 \mathrm{~m}^{3}$ de petit-lait.

D'après le procédé Polyvit, la levure est cultivée dans le petitlait avec toutes ses composantes, l'albumine y comprise, après que le phosphate a été mobilisé par addition de $\mathrm{HNO}_{3}$ ou d'un autre acide minéral et après avoir ajouté du $\mathrm{NH}_{3}$. Pendant la croissance de la levure, la valeur $\mathrm{pH}$ est de l'ordre de 5,0 et la température est de $35^{\circ} \mathrm{C}$ environ. En 16 à $18 \mathrm{~h}$, les matières nutritives de la levure sont entièrement consommées par l'espèce de Torula adaptée au substrat. La levure n'en est pas séparée, mais concentrée, avec le liquide résiduel, en pâte et transformée ensuite en matière sèche ou en extrait.

Lors de la production de levure dans le lactosérum suivant le procédé Waldhof, l'albumine, bien qu'elle soit précipitée par échauffement à $95^{\circ} \mathrm{C}$ par vapeur directe, n'est pas séparée du petit-lait. Après addition d'ammoniac et de sulfate d'ammonium ou aussi d'urée, ce petit-lait arrive en continu d'un bac d'alimentation (muni d'un agitateur pour empêcher la sédimentation des flocons d'albumine) à la cuve Waldhof; grâce à une durée de séjour de $3 \mathrm{~h} 30$ à à $4 \mathrm{~h}$, une valeur $\mathrm{pH} 3,0$ à 4,0 , une température de $33^{\circ} \mathrm{C}$ et une quantité d'air $\gamma$ nécessaire de 8 à $10 \mathrm{~m}^{3}$ pour $1 \mathrm{~kg}$ de matière sèche, la levure s'accroît normalement. La mousse d'une teneur en liquide de 40 à 50 p. 100 se décompose très facilement hors de la cuve et ne nécessite ni produit de démoussage, ni essoreuse.

La levure est séparée conjointement avec l'albumine, lavée une fois et séchée aussi rapidement que possible. Le produit sec a une teneur en albumine de 57 à 67 p. 100 et une teneur en graisse de 6 à 8 p. 100 . On a constaté un rendement de 20 à $25 \mathrm{~kg}$ de matière sèche de levure pour $1 \mathrm{~m}^{3}$ de lactosérum contenant 3,8 à 4,8 p. 100 de lactose. 
Par le procédé Biosyn, utilisé surtout dans les pays du bloc soviétique, on ne produit pas de levure mais du mycélium qui sert également de matière fourragère. On y cultive des champignons mycéliens [surtout des espèces particulières d'Oospora (Oïdium) lactis] en submersion dans le lactosérum qu'on agite et aère. Il est avantageux que ce mycélium puisse être isolé, sans séparateurs, et lavé directement sur un filtre à tambour sous vide, ce dernier revêtu d'une toile métallique à mailles fines. Par conséquent, le traitement en est nettement simplifié de façon que des installations moins importantes, raccordées aux fromageries, puissent encore travailler d'une façon rationnelle. En outre les besoins en eau de lavage sont relativement réduits. Mais par suite de la forte sensibilité aux acides du champignon, il faut que la culture en ait lieu près du point neutre, car le champignon s'accroît, d'une façon satisfaisante, seulement pour une valeur $\mathrm{pH}$ au-dessus de 5,8 ; il s'ensuit que des infections peuvent avoir lieu facilement de façon qu'une culture permanente devienne impossible. Après propagation stérile des cultures pures, on ne doit travailler en continu qu'aussi longtemps que les organismes étrangers ne prédominent. Le mycélium peut être séché sur un sécheur à bandes et broyé sur un moulin. On peut également sécher la masse du mycélium, suspendue dans l'eau, dans un atomiseur ou sur un séchoir à cylindres. Torula et Saccharomyces ne peuvent pas utiliser directement le lactosérum ; c'est pourquoi, lors du traitement du petit-lait, une hydrolyse doit précéder la culture de la levure. Par contre Candida pseudotropicalis et Sacch. fragilis sont à même d'assimiler le lactose.

\section{Influence de la production de la levure fourragère sur l'état des eaux résiduaires}

Le processus de putréfaction à l'abri de l'air des eaux résiduaires provenant de la production de la levure fourragère est celui qui convient le mieux. On les putréfie de la même manière que les eaux d'égouts urbains en produisant du méthane. Lors de la fermentation bactérienne anaérobie, les composés azotés se trouvent finalement réduits en $\mathrm{NH}_{3}$, les hydrates de carbone en $\mathrm{CO}_{2}$ et méthane.

Il se dégage un gaz à 60 p. 100 de méthane qui sera libéré du $\mathrm{CO}_{2}$ et $\mathrm{H}_{2} \mathrm{~S}$ par lavage sous pression et pourrait être utilisé productivement, étant donné que son pouvoir calorifique est de l'ordre de 5000 à $6000 \mathrm{kcal} / \mathrm{Nm}^{3}$; on produira ainsi environ $3,75 \mathrm{~m}^{3}$ de gaz pour $1 \mathrm{~m}^{3}$ d'eau résiduaire, La culture de la levure fourragère sur lactosérum provoque une diminution très économique de la charge initiale des régulateurs de régime, car elle y réduit la demande biochimique d'oxygène (D.B.O.) de 60 à 70 p. 100 et davantage. Les eaux résiduaires qui sortent de l'enceinte de putréfaction devront subir un traitement postérieur aérobie afin de les désodoriser, et ceci après passage par un bassin de décantation des boues.

Le traitement postérieur aérobie qui transforme l'ammoniac en nitrate (nitrification) est obtenu par le séjour des eaux résiduaires 
dans des pièces d'eau, en les faisant passer sur des lits bactériens et sur filtres d'arrosage ou encore par aération dans des bassins. Lorsqu'on dilue l'eau d'écoulement de l'enceinte de putréfaction à l'aide des eaux de rinçage et de refroidissement non traitées, avant de l'introduire dans le lit bactérien, on peut obtenir un effet d'épuration de 50 à 95 p. 100 et abaisser la D.B.O. à $100-200 \mathrm{mg} / 1$; ceci permet alors de déverser les eaux résiduaires épurées, conjointement avec l'eau de refroidissement, dans un petit régulateur de régime, et ceci sans préjudice.

L'incommodation de l'odorat due à la formation de $\mathrm{H}_{2} \mathrm{~S}$ (par bactéries réductrices de sulfates) lors de la putréfaction anaérobie peut être diminuée d'une façon importante, si, pour la culture de la levure fourragère, des chlorures sont employés à la place de produits nutritifs sulfatés.

En tout état de cause, lorsque les eaux résiduaires d'une installation de production de levure fourragère cultivée sur lactosérum sont épurées par le procédé biologique anaérobie décrit ci-dessus, le danger de pollution des eaux de rivières est nettement moindre que celui résultant du rejet du petit-lait non traité dans la rivière.

C'est pourquoi on s'occupe aux Etats-Unis de la culture de levure dans les eaux résiduaires saccharifères contenant aussi des protéines surtout en vue de la décharge des régulateurs de régime des entreprises industrielles.

\section{Conclusion}

La levure fourragère est un excellent aliment de bétail et sa culture sur le lactosérum de fromagerie est parfaitement possible, ce qui permet une meilleure utilisation du petit-lait souvent jeté dans la rivière la plus proche. Les différents procédés de culture de la levure fourragère sur le lactosérum de fromagerie sont décrits et l'influence de la production de cette levure sur l'état des eaux résiduaires (qui s'exprime par une forte diminution de la D.B.O.) est expliquée.

\section{S u m m a ry}

Fodder yeasts are an excellent cattle food, and their culture on the milk serum of cheesemaking is quite possible. This allows a better use of whey often thrown back into the nearest river. The different proceedings for cultivating fodder yeasts on the milk serum of cheesemaking are described in this statement.

The consequence of such a culture on the condition of waste water (which finds its expression in a strong diminution of BOD) is explained too. 